\title{
Clinical outcomes of nonoperatively managed degenerative cervical myelopathy: an ambispective longitudinal cohort study in 117 patients
}

\author{
*Allan R. Martin, MD, PhD, ${ }^{1,2}$ Sukhvinder Kalsi-Ryan, BScPT, PhD, ${ }^{3,4}$ Muhammad A. Akbar, MD, ,,2 \\ Anna C. Rienmueller, MD, ${ }^{2}$ Jetan H. Badhiwala, MD, PhD, ${ }^{1}$ Jefferson R. Wilson, MD, PhD, ${ }^{1}$ \\ Lindsay A. Tetreault, MD, PhD, ${ }^{2,5}$ Aria Nouri, MD, MSc, ${ }^{6}$ Eric M. Massicotte, MD, ${ }^{1,2}$ and \\ Michael G. Fehlings, MD, PhD',2
}

\begin{abstract}
'Division of Neurosurgery, Department of Surgery, University of Toronto; ${ }^{2}$ Division of Neurosurgery, Krembil Neuroscience Centre, Toronto Western Hospital, University Health Network, Toronto; ${ }^{3} \mathrm{KITE}$ Research Institute, University Health Network, Toronto; ${ }^{4}$ Department of Physical Therapy, University of Toronto, Ontario, Canada; ${ }^{5}$ Graduate Entry Medicine, University College Cork, Ireland; and ${ }^{6}$ Department of Neurosurgery, Geneva University Hospitals, Geneva, Switzerland
\end{abstract}

\begin{abstract}
OBJECTIVE Degenerative cervical myelopathy (DCM) is among the most common pathologies affecting the spinal cord but its natural history is poorly characterized. The purpose of this study was to investigate functional outcomes in patients with DCM who were managed nonoperatively as well as the utility of quantitative clinical measures and MRI to detect deterioration.
\end{abstract}

\begin{abstract}
METHODS Patients with newly diagnosed DCM or recurrent myelopathic symptoms after previous surgery who were initially managed nonoperatively were included. Retrospective chart reviews were performed to analyze clinical outcomes and anatomical MRI scans for worsening compression or increased signal change. Quantitative neurological assessments were collected prospectively, including modified Japanese Orthopaedic Association (mJOA) score; QuickDASH; graded redefined assessment of strength, sensation, and prehension-myelopathy version (GRASSP-M: motor, sensory, and dexterity); grip dynamometer; Berg balance scale score; gait stability ratio; and gait variability index. A deterioration of $10 \%$ was considered significant (e.g., a 2-point decrease in mJOA score).
\end{abstract}

RESULTS A total of 117 patients were included (95 newly diagnosed, 22 recurrent myelopathy), including 74 mild, 28 moderate, and 15 severe cases. Over a mean follow-up of 2.5 years, $57 \%$ (95\% Cl 46\%-67\%) of newly diagnosed patients and $73 \%$ (95\% Cl 50\%-88\%) of patients with recurrent DCM deteriorated neurologically. Deterioration was best detected with grip strength (60\%), GRASSP dexterity $(60 \%)$, and gait stability ratio $(50 \%)$, whereas the mJOA score had low sensitivity (33\%) in 50 patients. A composite score had a sensitivity of $81 \%$ and a specificity of $82 \%$. The sensitivity of anatomical MRI was $28 \%$ (83 patients).

CONCLUSIONS DCM appears to have a poor natural history; however, prospective studies are needed for validation. Serial assessments should include mJOA score, grip strength, dexterity, balance, and gait analysis. The absence of worsening on anatomical MRI or in MJOA scores is not sufficient to determine clinical stability.

https://thejns.org/doi/abs/10.3171/2020.9.SPINE201395

KEYWORDS degenerative cervical myelopathy; outcomes; nonoperative management

$\mathrm{D}$ EGENERATIVE cervical myelopathy (DCM) describes neurological impairment due to extrinsic compression of the spinal cord by degenerated intervertebral discs, ligaments, and vertebrae. ${ }^{1-3}$ DCM is probably the most common pathology directly affecting spinal cord function, although precise estimates of prev- alence and incidence are not available. ${ }^{3}$ The natural history of DCM is not well characterized, with an estimated $3 \%-62 \%$ rate of neurological deterioration over 2.5-8.2 years. ${ }^{4}$ However, previous studies may have underestimated the rate of deterioration because it can be subtle, and patients themselves may fail to perceive worsening due

ABBREVIATIONS CPGs = clinical practice guidelines; $D C M$ = degenerative cervical myelopathy; $\mathrm{eGVI}=$ enhanced gait variability index; GRASSP-M = graded redefined assessment of strength, sensation, and prehension-myelopathy version; $\mathrm{MDD}=$ mean detectible difference; $\mathrm{mJOA}=$ modified Japanese Orthopaedic Association; $\mathrm{SR}=$ stability ratio.

SUBMITTED July 28, 2020. ACCEPTED September 16, 2020

INCLUDE WHEN CITING Published online April 9, 2021; DOI: 10.3171/2020.9.SPINE201395.

${ }^{*}$ A.R.M. and S.K.R. share first authorship of this work. 
to mechanisms of behavioral adaptation and neuroplasticity. ${ }^{5,6}$ Meanwhile, the responsiveness of the widely used modified Japanese Orthopaedic Association (mJOA) scale has not been characterized.

Clinical management of DCM may consist of surgical decompression (with or without instrumented fusion) or nonoperative management, with serial assessments looking for deterioration. A variety of nonoperative therapies have been used, such as traction, physiotherapy, and cervical orthoses, but there is an absence of evidence to support their use. ${ }^{7}$ Surgical decompression not only halts deterioration but also provides significant neurological improvement in the majority of cases. ${ }^{8}$ Clinical practice guidelines (CPGs) recommend surgery for moderate to severe DCM, based on an mJOA score $<15 .{ }^{\circ}$ Optimal management of mild DCM (mJOA score 15-17) is controversial; operative and nonoperative management are valid treatment options, but surgery is recommended if neurological deterioration occurs. However, it is difficult to objectively detect neurological deterioration, particularly when it is subtle, given the complexity of spinal cord function and inherent limitations of clinical measures.

This study uses a comprehensive battery of clinical data to 1) better define the natural history of DCM managed nonoperatively; and 2) determine the utility of quantitative clinical measures and anatomical MRI to detect neurological worsening.

\section{Methods}

\section{Study Design and Subjects}

This study received research ethics board and institutional approval, and patients provided written informed consent. Subjects were enrolled prospectively from the clinics of two fellowship-trained spine neurosurgeons (M.G.F., E.M.M.) from May 2013 to July 2016. Criteria for DCM diagnosis included the following: $\geq 1$ symptom (sensory changes, hand clumsiness, gait imbalance, bladder dysfunction, weakness); $\geq 1$ sign (sensory deficit, motor deficit, hand incoordination, gait ataxia, hyperreflexia, Hoffman/ Babinski signs, spasticity); imaging showing spinal cord indentation, flattening, or circumferential compression from degenerative causes; and the absence of a more likely diagnosis. Subjects with clear neurological deficits from other conditions (e.g., stroke, diabetic neuropathy) were excluded; however, concomitant lumbar stenosis was allowed if it did not cause a motor deficit. Patients who had undergone previous surgery for DCM and subsequently developed new symptoms due to recurrent compression were analyzed separately. Per CPGs, ${ }^{9}$ surgical treatment was recommended at the initial visit for all patients with moderate or severe DCM unless there was a relative contraindication (e.g., excessive medical comorbidities) or additional investigations were required. All patients with DCM who were managed nonoperatively at the initial visit were booked for at least one follow-up visit, and subjects were included in the final analysis if they had multiple clinical assessments.

\section{Data Collection}

Natural history data were collected via retrospective chart reviews performed independently by two research- ers (A.R.M., A.C.R.), including dates of clinic visits, surgical procedures, and MRI studies, as well as clinic notes and radiology reports. The clinical case definition of neurological deterioration was based on the documented impression of the attending neurosurgeon during standard clinical assessment, including any of the following criteria: worsened neurological status (decreased motor strength, loss of sensation, deterioration in gait, deterioration of bladder function); decline in mJOA score by $\geq 2$ points; or a decline in spinal cord function as reported by the patient. The pattern of deterioration was considered rapid if marked deterioration occurred over $<3$ months, stepwise if marked deteriorations occurred at $\geq 1$ discrete points in time, steady if a consistent deterioration occurred, and subtle if minor or subjective deterioration occurred..$^{10}$ Subjects with multiple MRI studies overlapping the time period of clinical observation were included in the analysis. MRI reports by clinical neuroradiologists were reviewed to identify worsening spinal cord compression or increased spinal cord T2-weighted signal change.

Prospective data collection included a battery of quantitative clinical assessments administered by one of two experienced clinician-scientists (S.K.R., 18 years of experience; A.R.M., 10 years of experience) and required 30-45 minutes. Quantitative data included mJOA score (revised version, Table 1); QuickDASH; grip dynamometry; graded redefined assessment of strength, sensation, and prehension-myelopathy version (GRASSP-M: motor [power] grading in 10 muscle groups; sensory testing in C6, C7, and C8; and dexterity testing); ${ }^{11}$ spatiotemporal gait analysis (using GAITRite and Zeno electronic pressure mats, PKMAS software) including gait stability ratio (SR) and enhanced gait variability index (eGVI); and Berg balance scale (Table 2).

\section{Statistical Analysis}

Data tabulation was performed with Microsoft Excel for Mac 14.7.6. Statistical comparisons were performed with $\mathrm{R}$ version 3.0. Data were summarized by mean $\pm \mathrm{SD}$. The $95 \%$ confidence intervals in the proportion of patients in whom deterioration occurred were calculated using the Wilson procedure with correction for continuity. Proportions were compared with two-proportion z-tests. Changes in quantitative measures were analyzed in reference to the mean detectible difference (MDD) when available; otherwise, a deterioration $>10 \%$ was considered positive. A composite score was defined as showing deterioration if $\geq 3$ individual quantitative measures had deterioration greater than the MDD or $>10 \%$.

\section{Results \\ Subjects}

A total of 117 patients with DCM were included in the analysis (Fig. 1). Among these, 95 were newly diagnosed patients with DCM who were undergoing initial assessment and 22 had recurrent DCM associated with spinal cord compression at a different level (Table 3 ). The total cohort included 63 men and 54 women, and the mean age was $54.6 \pm 10.6$ years. The duration of symptoms was 75.6 \pm 109.3 months (ranging from 1 to 912 months), the base- 
TABLE 1. The mJOA scoring system

\begin{tabular}{|c|c|c|}
\hline Category & Score & Description \\
\hline \multirow[t]{6}{*}{ Upper-extremity motor subscore (of 5) } & 0 & Unable to move hands \\
\hline & 1 & Unable to eat with a spoon but able to move hands \\
\hline & 2 & Unable to button a shirt but able to eat with a spoon \\
\hline & 3 & Able to button a shirt with great difficulty \\
\hline & 4 & $\begin{array}{l}\text { Able to button a shirt with mild difficulty OR other mild fine motor dysfunction (marked } \\
\text { handwriting change, frequent dropping of objects, difficult clasping jewelry, etc.) }\end{array}$ \\
\hline & 5 & Normal hand coordination \\
\hline \multirow[t]{8}{*}{ Lower-extremity subscore (of 7) } & 0 & Complete loss of movement and sensation \\
\hline & 1 & Complete loss of movement, some sensation present \\
\hline & 2 & Inability to walk but some movement \\
\hline & 3 & Able to walk on flat ground with walking aid \\
\hline & 4 & Able to walk without walking aid, but must hold a handrail on stairs \\
\hline & 5 & Moderate to severe walking imbalance but able to take stairs without handrail \\
\hline & 6 & Mild imbalance when standing OR walking \\
\hline & 7 & Normal walking \\
\hline \multirow[t]{4}{*}{ Upper-extremity sensory subscore (of 3 ) } & 0 & Complete loss of hand sensation \\
\hline & 1 & Severe loss of hand sensation OR pain \\
\hline & 2 & Mild loss of hand sensation \\
\hline & 3 & Normal hand sensation \\
\hline \multirow[t]{4}{*}{ Urinary function subscore (of 3) } & 0 & Inability to urinate voluntarily (requiring catheterization) \\
\hline & 1 & Frequent urinary incontinence (more than once per month) \\
\hline & 2 & Urinary urgency OR occasional stress incontinence (less than once per month) \\
\hline & 3 & Normal urinary function \\
\hline
\end{tabular}

The mJOA is an 18-point score of functional disability specific to cervical myelopathy, including upper-extremity motor subscore, lower-extremity subscore, upper-extremity sensory subscore, and sphincter function. This version of the mJOA has been previously used and represents a slight modification of the version published by Benzel EC, Lancon J, Kesterson L, Hadden T. Cervical laminectomy and dentate ligament section for cervical spondylotic myelopathy. J Spinal Disord. 1991;4(3):286-295. ${ }^{2}$

line mJOA was $14.7 \pm 2.1$, and the severity of symptoms was mild (mJOA 15-17) in 74, moderate (mJOA 12-14) in 28 , and severe $(\mathrm{mJOA}<12)$ in 15 patients. The group with recurrent DCM was younger $(\mathrm{p}=0.03)$ and had a trend toward shorter duration of symptoms $(p=0.06)$, whereas other baseline characteristics were similar. The rationale for initial nonoperative management (at time of first clinical assessment) was due to mild symptoms or surgeon

\section{TABLE 2. Battery of clinical assessments for DCM}

\begin{tabular}{|c|c|}
\hline Clinical Measure & Description \\
\hline mJOA score ${ }^{2}$ & $\begin{array}{l}\text { 18-point ordinal scale of neurological impairment including subscores for upper-extremity motor function, lower- } \\
\text { extremity motor function (gait), upper-extremity sensory function, and urinary function }\end{array}$ \\
\hline QuickDASH ${ }^{21}$ & 44-point interval scale for upper-limb function, pain, and effects on quality of life \\
\hline ISNCSCI UEMS 22 & $\begin{array}{l}\text { 50-point interval scale for neurological function of the upper limb (power in } 10 \text { myotomes), administered separately for } \\
\text { each upper limb }\end{array}$ \\
\hline Jamar grip dynamometer ${ }^{23}$ & Measures maximal grip force in each hand; calculated as average of 3 measurements \\
\hline GRASSP-M ${ }^{10}$ & $\begin{array}{l}\text { Dexterity testing of each hand to place } 4 \text { metallic nuts on screws, scored for precision, grasp, number of drops, com- } \\
\text { pleteness (9 points), and time to completion }\end{array}$ \\
\hline Monofilament sensory testing ${ }^{24}$ & Semmes-Weinstein monofilaments applied to C6, C7, and C8 dermatomes of each hand to measure sensation \\
\hline Berg balance scale 25 & 56-point interval scale to measure balance while standing, transferring, and performing simple tasks \\
\hline GAITRite $^{26}$ & $\begin{array}{l}\text { Quantitative analysis of gait using an electronic pressure mat, measured with gait SR (single stance time/double } \\
\text { stance time) }\end{array}$ \\
\hline
\end{tabular}

ISNCSCI UEMS = International Standards for Neurological Classification of Spinal Cord Injury Upper Extremity Motor Score.

Various clinical assessments were selected to comprehensively assess common neurological and functional impairments that occur in DCM, including fine motor dysfunction of the hands, weakness, numbness, gait imbalance, and urinary difficulties. 


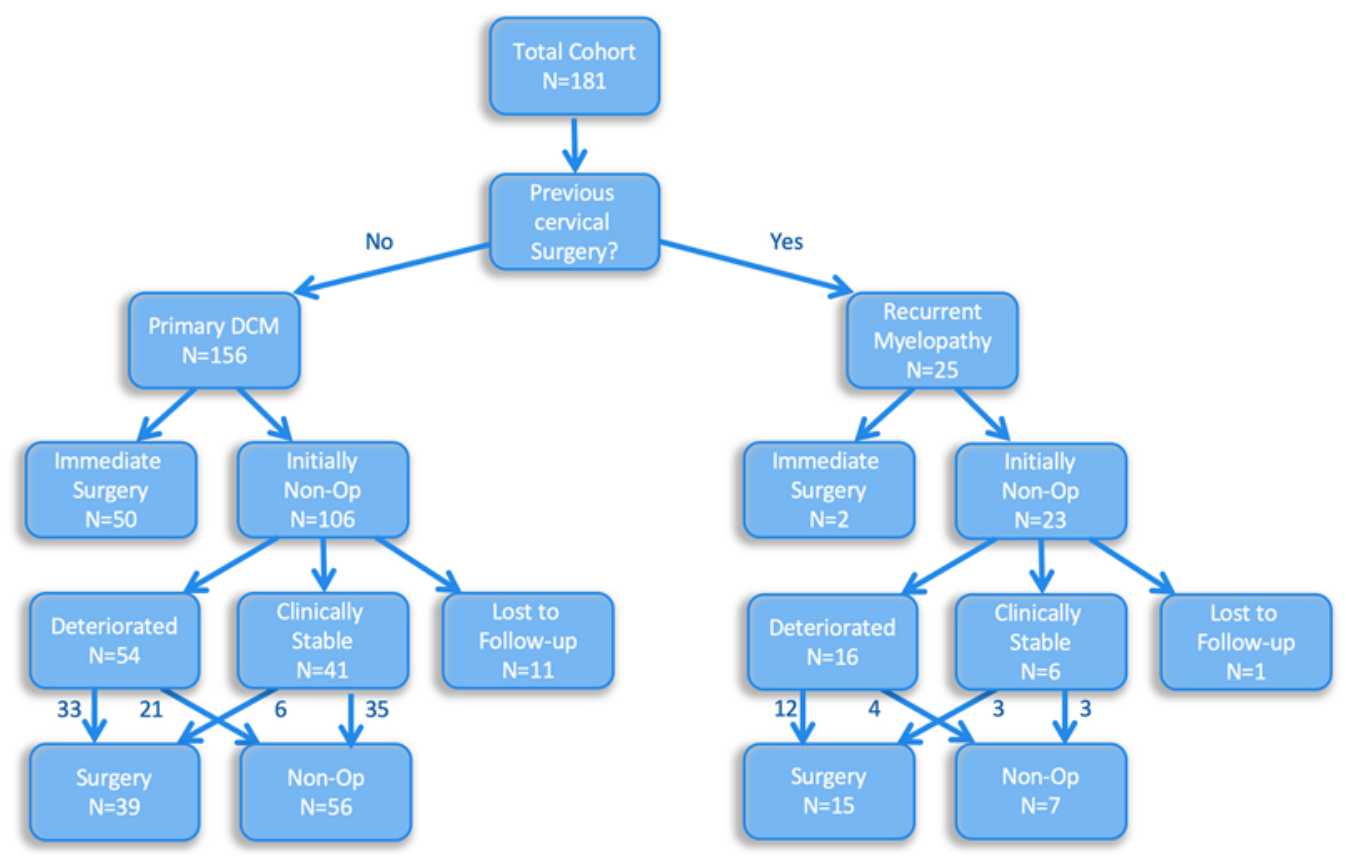

FIG. 1. Flowchart of clinical trajectories. Patients with DCM were enrolled prospectively and categorized as having recurrent myelopathy if they had previously undergone surgery for DCM, and as having primary DCM otherwise. Subjects were then classified based on the management plan selected during the first clinic visit with their treating surgeon; those with initial nonoperative management were the focus of this study. Clinical outcomes were determined via retrospective chart reviews of clinic follow-up visits, based on the surgeon's assessment of subjective and objective data. Treatment decisions were made based on established guidelines and shared decision-making between surgeon and patient. ${ }^{9}$ Figure is available in color online only.

preference in 63 patients $(58$ primary DCM, 5 recurrent DCM); due to patient preference in 24 patients (19 primary DCM, 5 recurrent DCM); and not documented in 30 (18 primary DCM, 12 recurrent DCM). Among 32 patients with moderate and severe primary DCM, nonoperative management was selected due to patient preference in 25 and not documented in 7 .

\section{Clinical Outcomes of DCM Managed Nonoperatively}

Fifty-four of 95 patients with primary DCM (57\%; $95 \%$ CI 46\%-67\%) experienced deterioration over $30.3 \pm 34.0$ months of follow-up. Categorized by initial severity, deterioration occurred in 31/63 patients with mild disease (49\%; 95\% CI 37\%-62\%), in 15/21 patients with moderate disease (71\%; 95\% CI 48\%-88\%), and in 8/11 patients with

TABLE 3. Demographics and baseline characteristics in 117 patients with DCM

\begin{tabular}{|c|c|c|c|c|}
\hline Characteristic & New DCM & Recurrent DCM & Combined & p Value \\
\hline No. of patients & 95 & 22 & 117 & \\
\hline Age in yrs & $55.7 \pm 10.3$ & $49.8 \pm 10.7$ & $54.6 \pm 10.6$ & $0.03^{*}$ \\
\hline Sex, M/F & $53: 42$ & $10: 12$ & 63:54 & 0.35 \\
\hline Duration of symptoms in mos (range) & $81.6 \pm 118.3(1-912)$ & $49.7 \pm 51.2(9-244)$ & $75.6 \pm 109.3(1-912)$ & 0.06 \\
\hline Baseline mJOA score & $14.8 \pm 2.1$ & $14.0 \pm 2.3$ & $14.7 \pm 2.1$ & 0.13 \\
\hline Severity & & & & 0.36 \\
\hline Mild & 63 & 11 & 74 & \\
\hline Moderate & 21 & 7 & 28 & \\
\hline Severe & 11 & 4 & 15 & \\
\hline Reason for nonop management & & & & 0.78 \\
\hline Not offered & 76 & 17 & 93 & \\
\hline Declined & 19 & 5 & 24 & \\
\hline
\end{tabular}

Characteristics of patients with a new diagnosis and those with recurrent symptoms of DCM are presented. Continuous variables are displayed as the mean \pm SD. Comparisons are made between groups using t-tests (2-tailed, unequal variance) for continuous variables and chi-square tests for categorical variables. ${ }^{*} p<0.05$. 
severe disease (73\%; 95\% CI 39\%-93\%); however, the difference in these proportions did not reach significance $(\mathrm{p}$ $>0.05$ ). Progression-free survival continued to diminish toward the end of the 5-year follow-up, although only 13 patients had follow-up beyond 5 years (Fig. 2). Surgery was offered to 43 patients who had deteriorated; among these, 33 underwent surgical treatment and 10 declined surgery. Eleven patients with subtle deterioration were managed nonoperatively via shared decision-making. Six of 41 patients who were clinically stable at follow-up decided to undergo surgery, including 4 who had previously declined surgery and 2 for whom the rationale was not documented.

\section{Neurological Deterioration in Recurrent Myelopathy}

Deterioration occurred in 16/22 patients (73\%; 95\% CI $50 \%-88 \%$ ) with recurrent DCM at another level over a follow-up of $32.4 \pm 37.1$ months. Categorized by initial severity, deterioration occurred in 8/11 patients with mild disease (73\%; 95\% CI 39\%-93\%), 4/7 patients with moderate disease (57.1\%; 95\% CI 20\%-88\%), and 4/4 patients with severe disease (100\%; 95\% CI 40\%-100\%); the difference in these proportions was not significant $(\mathrm{p}>0.05)$. Progression-free survival diminished consistently toward the 5-year follow-up, although only 4 patients had a follow-up of this duration (Fig. 2). Twelve patients in whom deterioration occurred and 3 who were clinically stable underwent surgery, whereas the remaining 7 did not have surgery.

\section{Pattern of Neurological Deterioration}

The pattern of neurological deterioration was steady in $38(55 \%)$, subtle in 27 (39\%), stepwise in 3 (4\%), and rapid in $1(1 \%)$. No differences were detected in the patterns when comparing primary and recurrent DCM or between DCM severity groups.

\section{Measurement of Neurological Deterioration}

In 50 patients with multiple quantitative assessments, the most sensitive measures to detect deterioration were grip strength (60\%), GRASSP dexterity (60\%), gait SR (50\%), and eGVI (44\%), whereas sensitivity was low for GRASSP power (0\%), GRASSP sensation (10\%), Berg balance scale score (31\%), mJOA score (33\%), and QuickDASH (36\%) (Fig. 3). The specificity of the quantitative measures was generally high, including GRASSP power (100\%), Berg balance scale score $(100 \%)$, mJOA score (93\%), eGVI (92\%), and GRASSP sensation (89\%). The composite score of quantitative measures had a sensitivity of $81 \%$ and a specificity of $82 \%$. In 83 patients with multiple anatomical MRI studies, the sensitivity to detect deterioration was $28 \%$ and the specificity was $70 \%$.

\section{Discussion}

This study used a battery of retrospective and prospective clinical data in a large cohort of patients to provide insight into the natural history of DCM and to improve the detection of neurological deterioration. The results suggest that the majority of patients with DCM who are managed nonoperatively will deteriorate neurologically

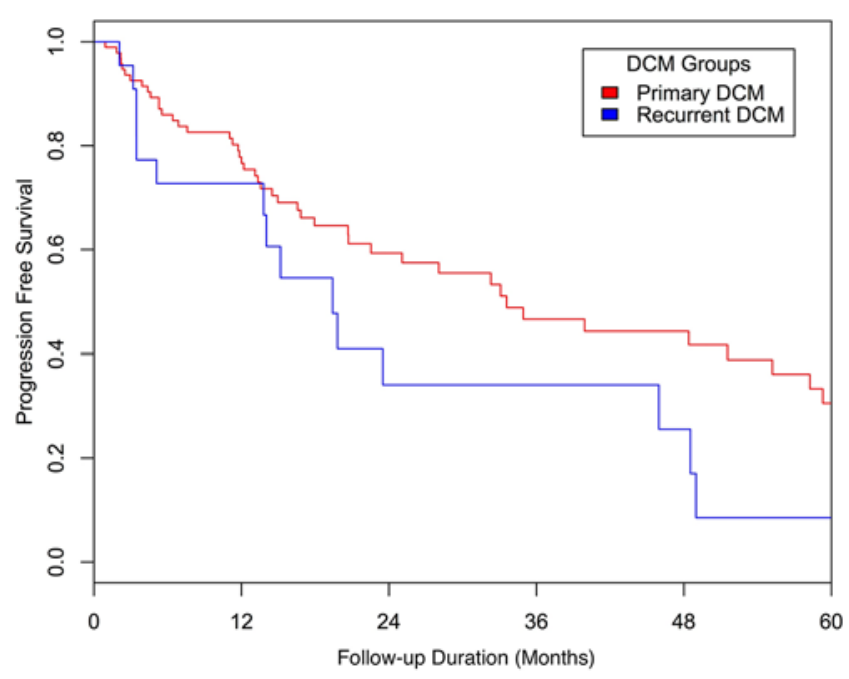

FIG. 2. Kaplan-Meier progression-free survival for patients with primary and recurrent $\mathrm{DCM}$. The figure displays the percentage of patients with primary and recurrent DCM who demonstrated no neurological deterioration over the time period of follow-up. Events are defined as neurological deterioration as assessed by the treating surgeon, with right-censoring of subjects with follow-up $<5$ years. Figure is available in color online only.

in short- to midterm follow-up. The likelihood of deterioration tended to increase with greater baseline severity, which is in keeping with current CPGs that recommend surgery for moderate and severe DCM. ${ }^{9}$ Furthermore, patients with mild DCM also demonstrated a relatively high risk of deterioration. The age of our cohort was similar to that in several previous DCM studies, ${ }^{8,12,13}$ indicating that the results of this study are generalizable. In summary, our findings suggest that DCM has an aggressive natural history, indicating that patients should be monitored closely for deterioration, which may include detailed education on the signs of worsening and surveillance assessments every 6-12 months. Furthermore, even patients in the mild DCM category may be better served with early surgery; however, further validation of these results in a large prospective study is needed to fully characterize the natural history of DCM and inform future CPGs.

For patients experiencing recurrent myelopathy, the results showed an even greater rate of neurological deterioration that uniformly occurred at a level adjacent to a previously fused segment. The high rate of progression in this group has several possible explanations: 1) it may be related to increased mechanical forces acting at the adjacent mobile segment; 2) it may be that patients with prior myelopathy are more vulnerable to new compression at another level due to a "second hit" phenomenon in which they have a reduced tolerance for further neurological injury; and 3) this group of patients may simply have more extensive multilevel disease prior to the first surgery, and deterioration would have occurred regardless of surgery.

The rate of deterioration in our data is similar to that reported by Yoshimatsu et al., ${ }^{14}$ who showed that $62 \%$ had deteriorated at 2.5 years, but was substantially higher than in other studies, in which the deterioration rate ranged 


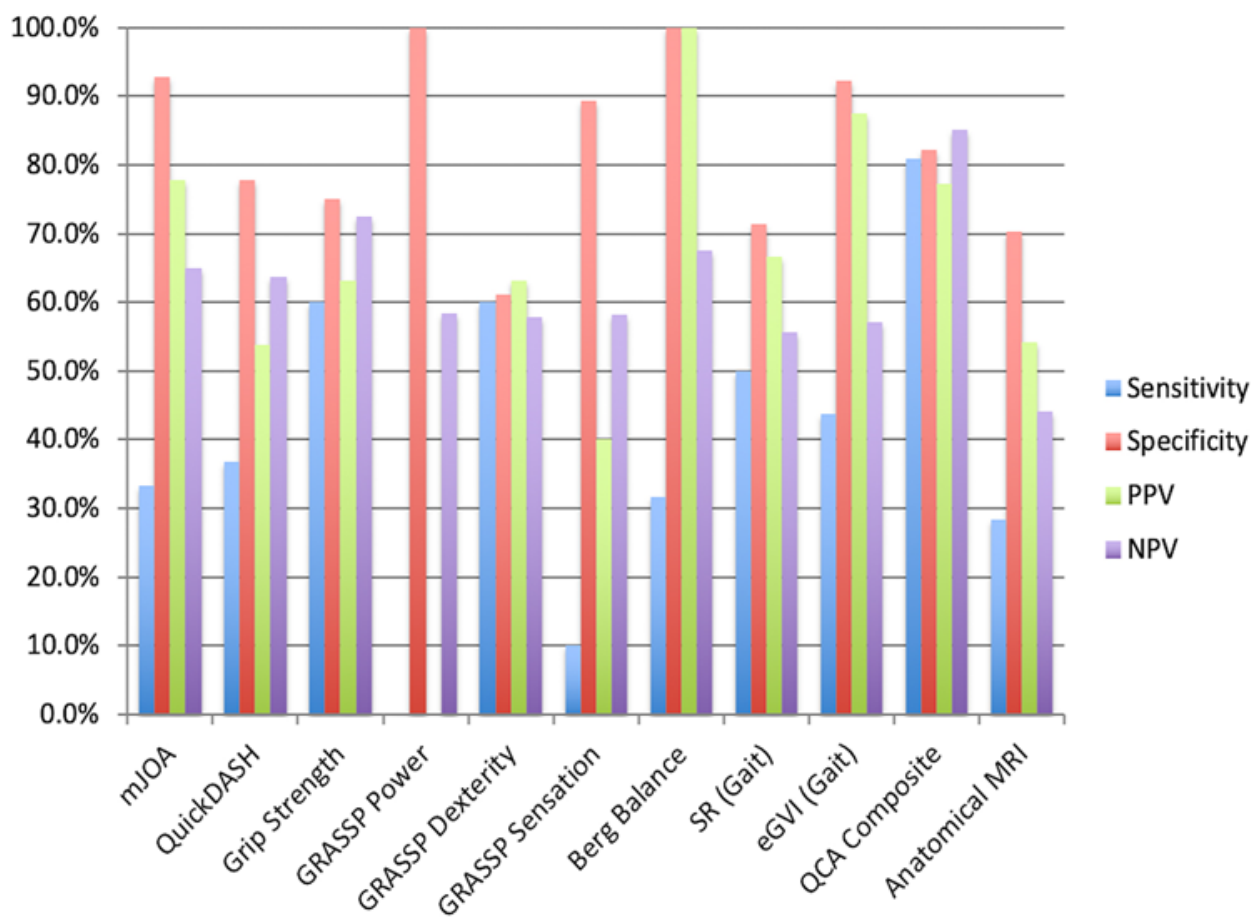

FIG. 3. Diagnostic accuracy of quantitative DCM measures. The diagnostic accuracies of various quantitative functional and neurological assessments $(n=50)$ and anatomical MRI $(n=83)$ were compared against the clinical case definition of neurological deterioration (the surgeon's clinical assessment). NPV = negative predictive value; PPV = positive predictive value; $Q C A=$ quantitative clinical assessment. Figure is available in color online only.

from $3 \%$ to $56 \%$ over $3.0-12.0$ years. ${ }^{13,15-20}$ These differences may be related to variable definitions of deterioration that exist throughout the literature. Our approach using the surgeon's impression of neurological deterioration as the clinical case definition was unique, incorporating objective and subjective data obtained through history and physical examination, while using the clinical acumen of the surgeon. However, this definition has the drawbacks of subjectivity and potential confirmation bias; furthermore, these data were extracted retrospectively. Overall, we believe that this was a valid approach because the surgeon's overall impression forms the basis on which to recommend surgical treatment. In contrast, most prior studies used the JOA or mJOA score and defined deterioration as a 1-point decrease ${ }^{4}$ However, the MDD of the mJOA score has not been established, and our group has previously found that the interobserver reliability of the mJOA score is only moderate, with differences between assessors averaging approximately 1 point ${ }^{21}$ Therefore, a 1-point change in mJOA score is probably not a reliable indication of deterioration, and mJOA score should be used in conjunction with other data, including the patient's subjective impression of deterioration, and with objective data via validated clinical instruments.

The investigation of quantitative clinical measures revealed that most individual instruments had poor sensitivity (i.e., responsiveness) to myelopathic progression, but good specificity. Surprisingly, the most sensitive measures were grip strength, hand dexterity, balance, gait SR, and eGVI. These findings support the use of GRASSP-M for upper-extremity motor function and spatiotemporal gait analysis, which have been previously demonstrated as useful measures of clinical impairment in patients with DCM. ${ }^{11,22}$ However, many of the measurements we used require specialized equipment and training, such as a grip dynamometer, GRASSP-M toolkit, ${ }^{11}$ and pressure-sensing walkway. The use of these tools in a standard clinic setting may not be feasible for some practitioners, but the results nonetheless highlight areas that should be assessed during history-taking physical examination and via alternative clinical instruments (e.g., 10-m timed up-and-go test). The low sensitivity of the mJOA score demonstrates an important limitation of this tool; although the mJOA score is a highly useful summary measure of the severity of DCM, it is a coarse measure that does not appear to be responsive to subtle deterioration. Ultimately, the utility of each specific clinical instrument is limited by the profound complexity of spinal cord function, which clinical measures can only quantify indirectly. Furthermore, clinical instruments are affected by numerous other factors, such as patient age, comorbidities, and physical disabilities. The approach of combining numerous clinical assessments into a composite score showed promising results, with the sensitivity and specificity both exceeding $80 \%$. Based on the results of this study, we propose an algorithm that incorporates multiple measures of spinal cord function to monitor patients for neurological deterioration (Fig. 4). In addition, continued efforts are needed to further refine and carefully validate clinical measures to provide robust detection of neurological deterioration. 


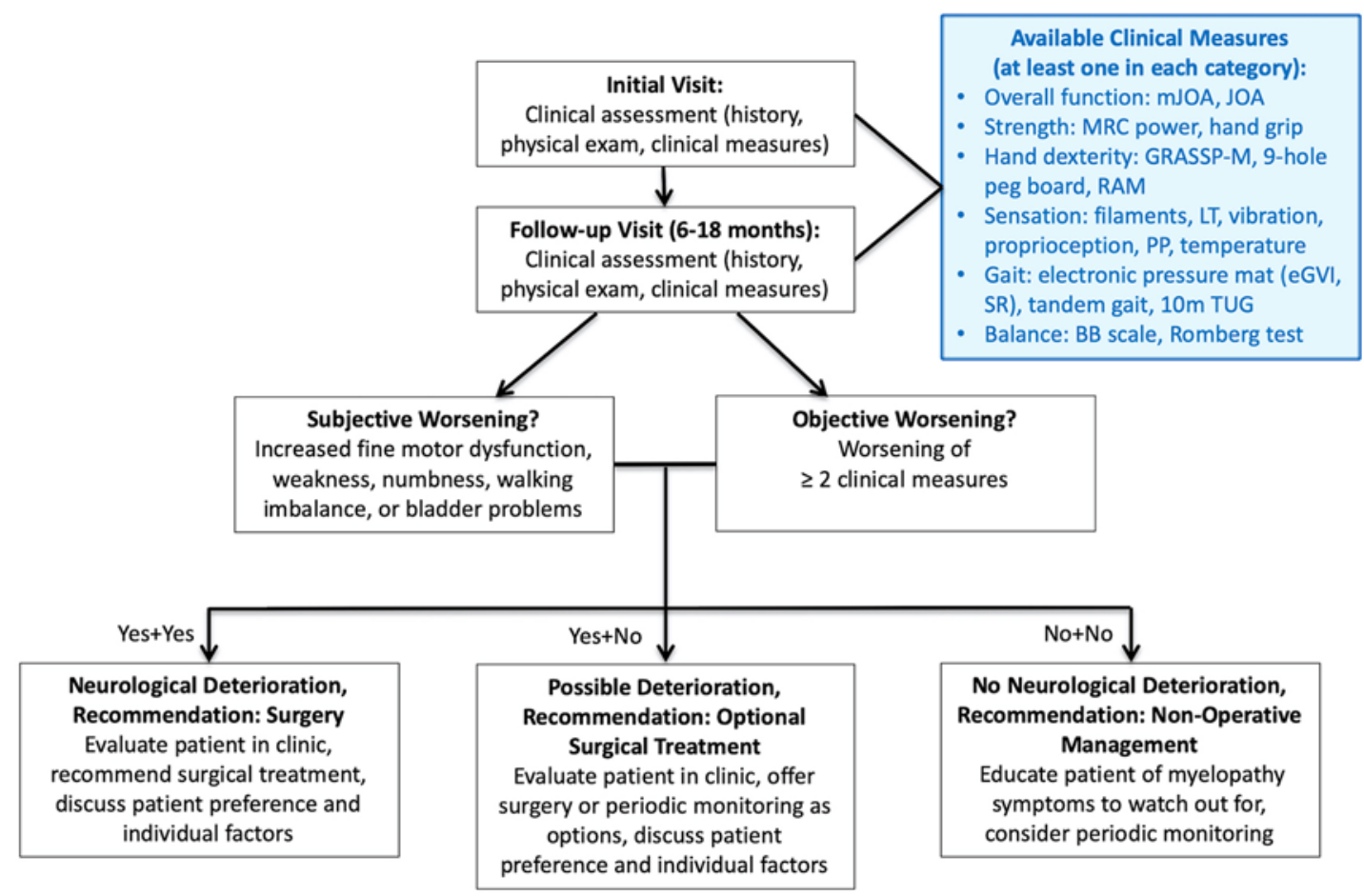

FIG. 4. Proposed clinical algorithm for monitoring patients with DCM for neurological deterioration. The proposed algorithm requires clinical data collection at 2 time points, including the patient's subjective impression of worsened spinal cord function, physical examination, and clinical measurements. The areas of focus for clinical measurements include overall spinal cord function, motor function, hand dexterity, sensation, gait, and balance; $\geq 1$ specific assessment tools for each of these areas are suggested, but these can be substituted for more feasible and/or convenient measures at the clinician's discretion. Further research is needed to fully validate this algorithm and the specific clinical instruments. BB = Berg balance; $L T=$ light touch; MRC = Medical Research Council; PP = pinprick; RAM = rapid alternating movements; TUG = timed up-and-go. Adapted from Martin AR, De Leener B, Cohen-Adad J, Kalsi-Ryan S, Cadotte DW, Wilson JR, et al. (2018) Monitoring for myelopathic progression with multiparametric quantitative MRI. PLoS One. 13(4):e0195733. ${ }^{5}$ C 2018 Martin et al. CC BY 4.0 (https://creativecommons.org/licenses/by/4.0/). Figure is available in color online only.

Our data demonstrated that the use of anatomical MRI to follow patients with DCM over time is a poor measure to detect neurological deterioration. The vast majority of patients who showed neurological deterioration had no change on MRI, in terms of both cord compression and intrinsic signal change. Furthermore, some patients in our cohort had more than 10 MRI studies over the period of observation. MRI is a limited resource, in terms of both timely access to scans and cost, and its routine use for serial imaging of DCM does not appear to be justified. We suggest that the primary utility of MRI in DCM is 1) to establish a diagnosis of DCM in conjunction with clinical findings, and 2) for surgical planning, once the decision to operate has been made.

This study is subject to a number of limitations that warrant discussion. First, the study of myelopathy is inherently limited by the myriad functions of the spinal cord and the current lack of ground truth data regarding neuronal injury. The natural history data reported in this study were a mixture of retrospective nonstandardized clinical assessments and MRI studies, which involved interpretation and categorization of notes into discrete categories. Selection bias is also a concern, given that patients who deteriorate are more likely to return for reassessment than patients who remain stable, but all patients enrolled in this study were planned for at least one follow-up assessment, and follow-up rates were very high (Fig. 1). Future prospective studies should be carefully designed to collect comprehensive data that accurately characterize myelopathic deficits, as well as subjective and objective measures of deterioration. Our study had multiple quantitative assessments in a subset of patients, and future studies will benefit from complete data collection in their entire cohort. Finally, patients in the cohort of individuals with DCM that we studied were referred for consideration of surgical treatment, which may not be representative of the entire population of individuals with DCM, because it may select for patients with greater severity of disease or with disease of a progressive nature who actively seek medical treatment.

\section{Conclusions}

The natural history of DCM in patients referred for surgical assessment appears to be aggressive, with a majority of patients experiencing neurological deterioration in a relatively short follow-up period. The high rate of deterioration suggests that patients should be monitored carefully for deterioration, and early surgery may be preferable, even 
in mild DCM. The mJOA score alone is not sufficient for clinical monitoring of myelopathic progression, and serial assessments should include quantitative grip strength, dexterity testing, balance, and gait analysis. The routine use of anatomical MRI for following patients is not warranted, and a lack of worsening should not be considered evidence of clinical stability. Future prospective studies are needed to confirm these findings and to inform the development of future CPGs for this important medical condition.

\section{Acknowledgments}

We are thankful for the Charles Kuntz Scholar Award, 2020 AANS/CNS Joint Section on Disorders of the Spine and Peripheral Nerves (A.R.M.); NREF Clinical Fellowship 2019-2020 (A.R.M.); CIHR Fellowship 2016-2017 (A.R.M.); CSRS-seed starter grant (S.K.R.); AO Spine Young Investigators Grant (S.K.R.); and Halbert Chair in Neural Repair and Regeneration (M.G.F.).

\section{References}

1. Nouri A, Tetreault L, Singh A, et al. Degenerative cervical myelopathy: epidemiology, genetics, and pathogenesis. Spine (Phila Pa 1976). 2015;40(12):E675-E693.

2. Benzel EC, Lancon J, Kesterson L, Hadden T. Cervical laminectomy and dentate ligament section for cervical spondylotic myelopathy. J Spinal Disord. 1991;4(3):286-295.

3. Badhiwala JH, Ahuja CS, Akbar MA, et al. Degenerative cervical myelopathy-update and future directions. Nat Rev Neurol. 2020;16(2):108-124.

4. Karadimas SK, Erwin WM, Ely CG, et al. Pathophysiology and natural history of cervical spondylotic myelopathy. Spine (Phila Pa 1976). 2013;38(22)(suppl 1):S21-S36.

5. Martin AR, De Leener B, Cohen-Adad J, et al. Monitoring for myelopathic progression with multiparametric quantitative MRI. PLoS One. 2018;13(4):e0195733.

6. Kalsi-Ryan S, Clout J, Rostami P, et al. Duration of symptoms in the quantification of upper limb disability and impairment for individuals with mild degenerative cervical myelopathy (DCM). PLoS One. 2019;14(9):e0222134.

7. Rhee JM, Shamji MF, Erwin WM, et al. Nonoperative management of cervical myelopathy: a systematic review. Spine (Phila Pa 1976). 2013;38(22)(suppl 1):S55-S67.

8. Fehlings MG, Wilson JR, Kopjar B, et al. Efficacy and safety of surgical decompression in patients with cervical spondylotic myelopathy: results of the AOSpine North America prospective multi-center study. J Bone Joint Surg Am. 2013; 95(18):1651-1658.

9. Fehlings MG, Tetreault L, Aarabi B, et al. A clinical practice guideline for the management of patients with degenerative cervical myelopathy: recommendations for patients with mild, moderate and severe disease and non-myelopathic patients with evidence of cord compression. Global Spine J. 2017;7(3)(suppl):70S-83S.

10. Bakhsheshian J, Mehta VA, Liu JC. Current diagnosis and management of cervical spondylotic myelopathy. Global Spine J. 2017;7(6):572-586.

11. Kalsi-Ryan S, Riehm LE, Tetreault L, et al. Characteristics of upper limb impairment related to degenerative cervical myelopathy: development of a sensitive hand assessment (Graded Redefined Assessment of Strength, Sensibility, and Prehension Version Myelopathy). Neurosurgery. 2020;86(3):E292-E299.

12. Fehlings MG, Ibrahim A, Tetreault L, et al. A global perspective on the outcomes of surgical decompression in patients with cervical spondylotic myelopathy: results from the prospective multicenter AOSpine international study on 479 patients. Spine (Phila Pa 1976). 2015;40(17):1322-1328.
13. Kadaňka Z, Bednařík J, Novotný $\mathrm{O}$, et al. Cervical spondylotic myelopathy: conservative versus surgical treatment after 10 years. Eur Spine J. 2011;20(9):1533-1538.

14. Yoshimatsu H, Nagata K, Goto H, et al. Conservative treatment for cervical spondylotic myelopathy. prediction of treatment effects by multivariate analysis. Spine J. 2001;1(4): 269-273.

15. Matsumoto $M$, Toyama $Y$, Ishikawa $M$, et al. Increased signal intensity of the spinal cord on magnetic resonance images in cervical compressive myelopathy. Does it predict the outcome of conservative treatment? Spine (Phila Pa 1976). 2000;25(6):677-682.

16. Shimomura T, Sumi M, Nishida K, et al. Prognostic factors for deterioration of patients with cervical spondylotic myelopathy after nonsurgical treatment. Spine (Phila Pa 1976). 2007;32(22):2474-2479.

17. Sumi M, Miyamoto H, Suzuki T, et al. Prospective cohort study of mild cervical spondylotic myelopathy without surgical treatment. J Neurosurg Spine. 2012;16(1):8-14.

18. Nakamura K, Kurokawa T, Hoshino Y, et al. Conservative treatment for cervical spondylotic myelopathy: achievement and sustainability of a level of "no disability". J Spinal Disord. 1998;11(2):175-179.

19. Oshima Y, Seichi A, Takeshita K, et al. Natural course and prognostic factors in patients with mild cervical spondylotic myelopathy with increased signal intensity on T2-weighted magnetic resonance imaging. Spine (Phila Pa 1976). 2012; 37(22):1909-1913.

20. Barnes MP, Saunders M. The effect of cervical mobility on the natural history of cervical spondylotic myelopathy. $\mathrm{J} \mathrm{Neu-}$ rol Neurosurg Psychiatry. 1984;47(1):17-20.

21. Martin AR, Kalsi-Ryan S, Akbar MA, et al. The natural history of degenerative cervical myelopathy. Paper presented at: 36th Annual Meeting of the AANS/CNS Section on Disorders of the Spine and Peripheral Nerves; March 5-8, 2020; Las Vegas, NV.

22. Kalsi-Ryan S, Rienmueller AC, Riehm L, et al. Quantitative assessment of gait characteristics in degenerative cervical myelopathy: a prospective clinical study. J Clin Med. 2020; 9(3):752-763.

23. Hamilton GF, McDonald C, Chenier TC. Measurement of grip strength: validity and reliability of the sphygmomanometer and Jamar grip dynamometer. J Orthop Sports Phys Ther. 1992;16(5):215-219.

24. Ellaway PH, Catley M. Reliability of the electrical perceptual threshold and Semmes-Weinstein monofilament tests of cutaneous sensibility. Spinal Cord. 2013;51:120-125.

25. Berg KO, Wood-Dauphinee SL, Williams JI, Maki B. Measuring balance in the elderly: validation of an instrument. Can J Public Health. 1992;83(suppl 2):S7-S11.

26. Webster KE, Wittwer JE, Feller JA. Validity of the GAITRite walkway system for the measurement of averaged and individual step parameters of gait. Gait Posture. 2005;22(4): 317-321.

\section{Disclosures}

Dr. Kalsi-Ryan owns Neural Outcomes Consulting, Inc., which manufactures and distributes GRASSP products, and she is also the inventor who collects royalties (with University Health Network as the licensing body). Dr. Wilson is a consultant for Stryker Canada.

\section{Author Contributions}

Conception and design: Fehlings, Martin, Kalsi-Ryan, Wilson, Massicotte. Acquisition of data: Martin, Kalsi-Ryan, Akbar, Rienmueller, Badhiwala, Tetreault, Nouri. Analysis and interpretation of data: Fehlings, Martin, Kalsi-Ryan, Akbar, Rienmueller, Badhiwala, Wilson, Tetreault, Nouri. Drafting 
the article: Martin, Kalsi-Ryan. Critically revising the article: Fehlings, Martin, Kalsi-Ryan, Badhiwala, Nouri, Massicotte. Reviewed submitted version of manuscript: all authors. Approved the final version of the manuscript on behalf of all authors: Fehlings. Statistical analysis: Martin, Kalsi-Ryan, Badhiwala. Administrative/technical/material support: Fehlings. Study supervision: Fehlings.

\section{Supplemental Information}

\section{Previous Presentations}

This work was previously presented at the 36th Annual Meeting of the AANS/CNS Section on Disorders of the Spine and Peripheral Nerves, Las Vegas, NV, March 6, 2020; and at the 20th Annual Scientific Conference of the Canadian Spine Society, Whistler, BC, Canada, February 27, 2020.

\section{Current Affiliations}

Dr. Martin: Department of Neurological Surgery, University of California, Davis, CA.

\section{Correspondence}

Michael G. Fehlings: University of Toronto, Toronto Western Hospital, Toronto, ON, Canada.michael.fehlings@uhn.ca. 